Results 36 Hotspots were identified. QCA revealed 40\% of crash sites were found on local roads, without night lighting and had increased motorcycle density. A further $26 \%$ of hotspots were located on paved narrow roads and 13\% of hotspots were described as unpaved roads with uneven roadside areas. Roadside unevenness was more predominate in low risk sites, (High risk $\mathrm{n}=7$ (46.7\%), Low risk $\mathrm{n}=19,90.5 \%, \mathrm{p}=0.01)$. Both low and high risk sites had minimal signage (High risk $n=1(6.7 \%)$, low risk $\mathrm{n}=6(28.6 \%)$ and all had informal pedestrian pathways (High risk $\mathrm{n}=15$ (100\%), low risk $\mathrm{n}=21(100 \%)$.

Conclusions In Moshi, Tanzania hotspots were associated with roadside dangers, lack of night lighting, informal pedestrian pathways, and increased traffic density but overall there was little variability between the low and high risk sites suggesting hazardous road conditions exist throughout the area. Our findings suggest overall improvement in municipal infrastructure, including structural improvements, signage and enforcement are needed to help reduce road traffic injury burden.

\section{WHY UNSAFE AND VULNERABLE HIGHWAY IN BANGLADESH?}

Soyab Ali. Dhaka Metropolitan Police (DMP), Bangladesh Trainer on Defensive Driving and Occupational Safety

\subsection{6/injuryprev-2016-042156.872}

Background Safe Highway is a multifunctional issue and requires more attention to reduce the ever increasing of road crashes and accidents. Vehicles using National and Regional Highways (NRH) in Bangladesh have a wide variation in operating characteristics with a combination of motorised and nonmotorised form of transports such as farm tractors, animal carts; tricycles taxies (Rickshaw) which share the same road of first moving motorize traffic. There are thousands of roadside markets and other infrastructures which dangerous and threat In addition extensive practices of pedestrians Jaywalking and illegal road crossing by foot due to lack of overhead crossing often contribute to cause. Pedestrian activity is also high in these stretches. Considering all these in mind and to make the Highways safer, we have to take integral program combining the every component responsible for safety issue.

Methods Use Police HQ MAPS data/Accident Research Centre (ARC) library and Bangladesh Road Transport Authority (BRTA) annual report, 2014-15 and newspaper cutting.

Results Road worthy vehicles can reduce accidents \& congestion in great number. Chaotic traffic movement and congestion on road are very common in Bangladesh is rated 15 one of the high risk country in the world. There are thousands of roadside markets and other infrastructures which dangerous and threat. As a cost on an average 12-14 people killed every day and annually 4200 on and average which affect $1.8 \%$ of GDP.

Cars, buses and trucks frequently drive at high speed without headlights illuminated or on full beam. Drivers overtake other vehicles at inappropriate moments and causes head-on collisions. Conclusions We need to educate the citizens, require strong political commitment from government and provide proper facilities to avoid road accident and loss of life by traffic crash.

Components in Highways there are about $3886 \mathrm{~km}$ National Highway and $1751 \mathrm{~km}$ Regional Highway in our country owned by Roads and Highways Division-RHD. There are few Highways in Bangladesh, which cover International Standard. Only recently build few Highways only fulfilled few criteria of international quality

Mix Traffic using highways and local made poor standard vehicle like local made nonnotarized transport, Human Pulling Rickshaw, Bicycle, horse and bull carts.

Roadside Markets like shops, village market, Hawkers, workshops, mosque and schools

Other infrastructure bi-lane, shoulder, road makings, median road signs, uneven surface, straight sub-lane, small shoulder and without road shoulder, muddy side road, poor design of median, poor road markings, poor road signs are common phenomenon of our existing highways.

\section{GOALS FOR RIDER EDUCATION: ADAPTATION OF FINNISH GOALS FOR DRIVER EDUCATION MODEL FOR MOTORCYCLISTS}

${ }^{1}$ Teresa Senserrick, ${ }^{2}$ Duncan McRae, ${ }^{3}$ Phil Wallace, ${ }^{1}$ Ann Williamson, ${ }^{4}$ Liz de Rome. 'University of New South Wales, Australia; ${ }^{2}$ Youthsafe, Australia; ${ }^{3}$ Learning Systems Analysis, Australia; ${ }^{4}$ LdeR Consulting, Australia

\subsection{6/injuryprev-2016-042156.873}

Background The authors were commissioned to develop education curricula for a new motorcyclist graduated licensing system in Victoria, Australia. A review of published literature identified several promising models internationally, but no single best-practice framework. The objective of this research was to determine whether a best-practice framework implemented for new drivers, the Finnish Goals for Driver Education (GDE; Keskinen, 1996), could be adapted and applied for new motorcyclists. The model comprises four levels: basic, tactical, strategic and general.

Methods An adapted framework was drafted by replacing driverspecific content to motorcyclist-equivalent content where applicable (e.g. seatbelts to helmets). Curriculum materials were drafted using the framework as a guide, focusing on the five most frequent novice motorcyclist crash types in Victoria and particularly enhancing the roadcraft content of the tactical and strategic levels. Train-the-trainer pilots were offered to experienced motorcycle trainers with one medium-sized provider in Victoria, and the option to undertake the pilot programs offered to their learner permit and licence candidates on selected weeks in March to October 2015. Student pilots were conducted to saturation, that is, until no new feedback was obtained. University Ethics approval was obtained.

Results In total, 10 trainers and 53 students took part in the pilots. Saturation was achieved in 6 pilots each for pre-learner course, and combined learner and licence course components. Feedback from participants showed strong support for the curriculum and suggested that all levels of the model had been addressed.

Conclusions The results suggested that the GDE model had been readily adapted into a promising framework for improving novice motorcyclist education. The Victorian Government has commenced plans to conduct a pre-post outcome evaluation of the new curriculum, which is due to commence rollout across the state in March 2016. 